ScIDice

\section{Comparative Evaluation Of Remineralisation Potential Of Fluoridated Toothpaste And Toothpaste Containing Blue Covarine - An Invitro Study}

Research Article

Sathya Kumaresan ${ }^{1}$, L.Leelavathi ${ }^{2 *}$, Meignana Arumugham Indiran ${ }^{3}$

${ }^{1}$ Post Graduate, Department Public Health Dentistry, Saveetha Dental College, Saveetha Institute of Medical and Technical Sciences, Saveetha University, No.162, Poonamallee high Road, Chennai 600077, Tamil Nadu, India.

2 Department of Public Health Dentistry, Saveetha Dental College, Saveetha Institute of Medical and Technical Sciences, Saveetha University, No.162, Poonamallee high Road, Chennai 600077, Tamil Nadu, India.

3 Professor and Head, Department of Public Health Dentistry, Saveetha Dental College, Saveetha Institute of Medical and Technical Sciences, Saveetha University, No.162, Poonamallee High Road, Chennai 600077, Tamil Nadu, India.

Abstract

Introduction: An Ideal toothpaste is the one that causes minimal abrasion and surface roughness on tooth and restorative materials. Hence, the aim of the current study was to evaluate the remineralization potential of fluoridated toothpaste and toothpaste containing blue covarine .

Materials and Methods: This in vitro study involves 12 enamel samples divided into two groups of 6 samples each. The remineralizing agents included were Pepsodent Whitening toothpaste and Colgate Maxfresh toothpaste. The two groups were subjected to demineralization following which the groups were remineralized with their respective remineralizing toothpastes. Statistical Analysis: Paired t-test was used for intragroup comparison and independent t-test was used for intergroup comparison.

Results: On intragroup comparison, the mean values of microhardness in group Pepsodent Whitening toothpaste at baseline and after remineralization were $474.36+\_29.26$ and $479.93+\_29.19$ respectively.

Similarly, the mean values of microhardness in group Colgate Maxfresh toothpaste at baseline and after remineralization were $490.51+\_18.55$ and $501.5+\_18.75$ respectively and was statistically significant with $\mathrm{p}=0.000$.

On intergroup comparison, the mean values of microhardness in group Pepsodent Whitening toothpaste and Colgate Maxfresh post remineralization were $479.93+\_29.19$ and 501.50+_18.75 respectively and the difference was not statistically significant with $\mathrm{p}=0.315$. As per statistical analysis, there was an improved enamel remineralization in Colgate Maxfresh toothpaste group as compared to Pepsodent Whitening toothpaste group

Conclusion: The results of this in vitro study showed that Colgate Maxfresh is likely to yield higher microhardness when compared to Pepsodent Whitening toothpaste.

Keywords: Blue Covarine Toothpaste; Fluoridated Toothpaste; Early Enamel Lesions; pH Cycling; Surface Microhardness.

\section{Introduction}

Caries is a highly prevalent multifactorial disease [1]. The carious lesion is initiated by demineralization favouring factors such as fermentable carbohydrates, cariogenic bacteria and salivary dysfunctions. These pathological factors gradually win over protective factors such as remineralizing ions present in saliva [2]. Dental caries is a public health concern that can be minimized in the ini- tial stages of demineralisation through remineralisation $[3,4]$. As a result, dental professionals have shifted to the noninvasive management of carious lesions using remineralizing toothpastes [5]. Remineralizing toothpastes serve as an interventional approach for the management of early enamel lesion [6].

Till date, the researches in the literature reinforce that fluoride treatment remains the potent remineralizing method for early

\footnotetext{
*Corresponding Author:

L.Leelavathi,

Department of Public Health Dentistry, Saveetha Dental College, Saveetha Institute of Medical and Technical Sciences, Saveetha University, No.162, Poonamallee high Road, Chennai 600077, Tamil Nadu, India.

E-mail: leelavathi.sdc@saveetha.com
}

Received: April 20, 202

Accepted: July 09, 2021

Published: July 21, 2021

Citation: Sathya Kumaresan, L.Leelavathi, Meignana Arumugham Indiran. Comparative Evaluation Of Remineralisation Potential Of Fluoridated Toothpaste And Toothpaste Containing Blue Covarine - An Invitro Study. Int J Dentistry Oral Sci. 2021;8(7):3460-3464. doi: http://dx.doi.org/10.19070/2377-8075-21000706

Copyright: L.Leelavathi 2021 . This is an open-access article distributed under the terms of the Creative Commons Attribution License, which permits unrestricted use, distribution and reproduction in any medium, provided the original author and source are credited. 
enamel caries. There is evidence based literature on the remineralisation potential of agents like Novamin, tricalciumphosphate, Nanohydroxyapatite [7], casein phosphopeptide amorphous calcium phosphate(CPP-ACP), casein phosphopeptide amorphous calcium phosphate with fluoride(CPP-ACPF) [8-11]. Since the 1950s, fluoride has been considered the gold standard in caries prevention. According to several epidemiological data, caries rate is either stagnating or notwithstanding the regular use of fluoride toothpastes [12]. In the era of holistic dentistry and after fluoride has been categorized as a chemical neurotoxicant, major thriving concerns arise regarding the exposure of fluoride to children from multiple sources accelerating the risk of developing dental fluorosis [13].

It is well known that toothpaste is an important vehicle for delivering therapeutic agents to the oral cavity during the daily brushing routine. Many types of toothpaste ingredients have been described in the literature for removing plaque, extrinsic stains and teeth whitening .However, these include abrasives, calcium chelators and surfactants which are known to cause surface hardness and roughness on tooth [14]. According to studies, silica based blue covarine toothpastes have shown minimal undue degree of abrasivity to enamel or dentin compared to other relevant commercially available products [15].

Predominantly, silica based blue covarine toothpastes are advocated for teeth whitening where it changes the optical properties of teeth [16]. Despite abundant literature on teeth whitening of Blue covarine, its effect on remineralization potential is limited and none of the studies have compared its efficacy with fluoride. Hence, the study aimed at quantitatively evaluating remineralization potential of fluoridated toothpaste and a toothpaste containing blue covarine.

\section{Materials And Methods}

This in vitro study was conducted in the Laboratory (White lab), Saveetha Dental College, Chennai. Vickers microhardness values were analyzed in Mettex Laboratories Pvt Ltd, Guindy, Chennai.

\section{Inclusion criteria}

Permanent maxillary premolars extracted for orthodontic purposes were selected for the study. The teeth selected were non carious, with an intact surface, no visible cracks and were unrestored.

\section{Exclusion criteria}

Any tooth with visible cracks, hypoplasia, enamel white spot lesions or caries on any surface and restored teeth.

\section{Sample preparation}

12 freshly extracted human maxillary premolars were used in the study. After thorough scaling with an ultrasonic scaler and polishing with a pumice paste and a rubber cup, the teeth were examined for visible cracks under microscope at 10 magnification. The radicular part of each of the teeth was horizontally sectioned at a level of $1 \mathrm{~mm}$ apical to cementoenamel junction with the help of a diamond disc at $15000 \mathrm{rpm}$ with constant coolant.
Enamel samples of $2 \mathrm{~mm}$ thickness were prepared on the lingual surfaces of the teeth using a double faced diamond disc mounted on a contra angle handpiece (Fig.1). Following sample preparation, windows were created with a dimension of $5 \mathrm{~mm}$ X $5 \mathrm{~mm}$ using adhesive tape (Fig.2). And now, the samples were coated with a nail varnish to make them acid resistant.

After drying, the adhesive tape was removed from the enamel using a sharp tipped instrument exhibiting a rectangular area on the enamel surface [17].

\section{Groups}

A total of 12 enamel slabs were randomly divided into two groups of 6 samples each based on the type of remineralizing agent used. Now, the specimens were mounted in acrylic resin moulds by pouring selfcure acrylic resin in the preformed mould of $2 \mathrm{~cm} \mathrm{X}$ $2 \mathrm{~cm}$ (Fig.3). Following this, all the samples were tested for baseline surface microhardness measurement by Vickers Hardness Tester (Leco model M-400)

\section{Slurry preparation}

The remineralizing agent slurry was prepared by manually mixing peanut sized toothpaste to the distilled water (three times the volume of toothpaste) with a plastic spatula at a speed of 30 rotations in $30 \mathrm{~s}$.

\section{$\mathrm{pH}$ cycling model}

This was adopted to simulate the dynamic process of demineralisation and remineralisation process that occurs in the oral cavity. Each of the twelve samples were treated with the respective remineralizing agents Pepsodent whitening-blue covarine containing toothpaste and Colgate maxfresh-standard fluoridated toothpaste for $2 \mathrm{~min}$, following which the samples were immersed separately in $20 \mathrm{ml}$ of demineralizing solution (calcium $2.0 \mathrm{mMol} / \mathrm{L}$, phosphate $2.0 \mathrm{mMol} / \mathrm{L}$, acetic acid $75.0 \mathrm{mMol} / \mathrm{L}$, adjusted to $\mathrm{pH} 4.4$ ) for a period of $3 \mathrm{~h}$. This was followed-up with treatment of the samples again with remineralizing agents for $2 \mathrm{~min}$. The remineralizing solution was replaced every $48 \mathrm{~h}$ and the demineralizing agent replaced every 5 days. The $\mathrm{pH}$ cycling was carried out for a period of 28 days. After the completion of the process of $\mathrm{pH}$ cycling, all the groups of samples were assessed for surface microhardness using Vickers hardness test.

\section{Microhardness testing}

The specimen surfaces were assessed for microhardness using Vickers microhardness testing machine(Fig.4). A load of $100 \mathrm{~g}$ was exercised steadily to the surface of specimens for $10 \mathrm{~s}$ using Vickers elongated diamond pyramid indenter under a $\times 40 \mathrm{ob}-$ jective lens (Fig.5.). The Vickers Indenter Test was performed, with indentations at least $120 \mu \mathrm{m}$ apart, and the average of the 3 indentations was measured as the average value. Accuracy of values of diagonal length of indentation was determined under high magnification of $\times 400$. The Vickers values were converted into microhardness values.

The results were analyzed by Paired t test that compared the baseline and post remineralisation values. Independent $t$ test that compared values between two toothpaste groups. 
Figure 1. Enamel specimens of $2 \mathrm{~mm}$ thickness.

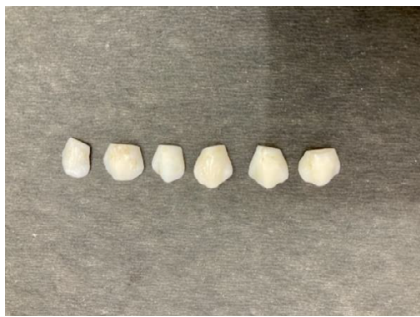

Figure 2. Windows with a dimension of $5 \mathrm{mmX} 5 \mathrm{~mm}$ and covered using an adhesive tape.

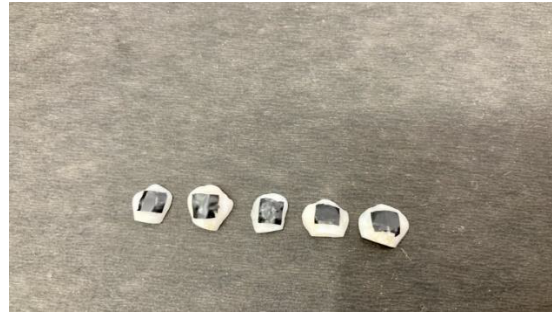

Figure 3. The specimens are mounted on acrylic blocks.

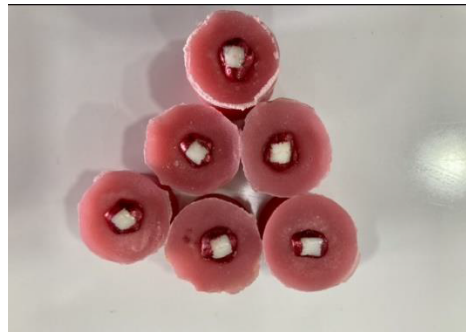

Figure 4. Vickers Hardness Tester (Leco model M-400).

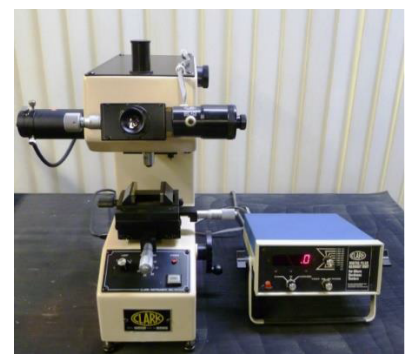

Figure 5. Acrylic blocks subjected to load.

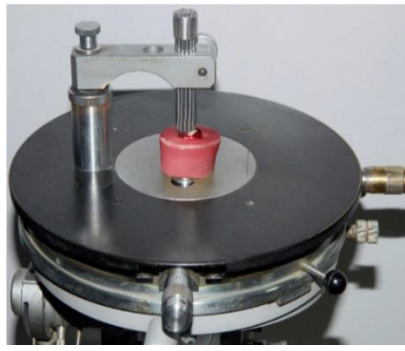

\section{Results}

The data were processed through SPSS software version 23.The Kolmogorov-Smirnov test was used to test the normality of the data. Paired t-test was used for intragroup comparison and independent t-test was used for intergroup comparison.

Table 1. shows intragroup comparison; the mean values of microhardness in group Pepsodent Whitening toothpaste at baseline and after remineralization were $474.36+\_29.26$ and $479.93+\_29.19$ respectively.
Similarly, the mean values of microhardness in group Colgate Maxfresh toothpaste at baseline and after remineralization were $490.51+\_18.55$ and $501.5+\_18.75$ respectively and was statistically significant with $\mathrm{p}=0.000$.

Table 2. shows intergroup comparison, the mean values of microhardness in group Pepsodent Whitening toothpaste and Colgate Maxfresh at baseline were $474.36+29.26$ and $490.51+\_18.55$ respectively and the difference was not statistically significant with $\mathrm{p}=0.282$ 
Table 1. Intragroup comparison of microhardness values.

\begin{tabular}{|c|c|c|c|}
\hline & N & Mean+_SD & P \\
\hline Pepsodent Whitening & & & \\
Baseline Microhardness & 6 & $474.36 \pm 29.26$ & 0.000 \\
Microhardness after remineralization & 6 & $479.93 \pm 29.19$ & \\
\hline Colgate Maxfresh & & & \\
Baseline Microhardness & 6 & $490.51 \pm 18.55$ & 0.000 \\
Microhardness after remineralization & 6 & $501.5 \pm 18.75$ & \\
\hline
\end{tabular}

Table 2. Intergroup comparison of microhardness value.

\begin{tabular}{|c|c|c|c|}
\hline & N & Mean+_SD & P \\
\hline Microhardness difference at baseline & & & \\
Pepsodent Whitening & 6 & $474.36+\_29.26$ & 0.282 \\
Colgate Maxfresh & 6 & $490.51+\ldots 18.55$ & \\
\hline Microhardness difference after remineralization & & & \\
Pepsodent Whitening & 6 & $479.93+\_29.19$ & 0.315 \\
Colgate Maxfresh & 6 & $501.5+\_18.75$ & \\
\hline
\end{tabular}

The results showed that both toothpastes were able to produce similar levels of microhardness following remineralization procedures. However, the amount of microhardness was considerably high with Colgate Maxfresh toothpaste than Pepsodent Whitening toothpaste. This signifies that Colgate Maxfresh possesses improved remineralization than Pepsodent Whitening toothpaste although it was not statistically significant.

\section{Discussion}

The equilibrium between demineralization and remineralization is largely intervened by the acidic environment produced by the bacteria and the buffering capacity of saliva intraorally $(16,18)$.A fall in $\mathrm{pH}$ of the oral cavity results in tooth demineralization. On the contrary, a rise in $\mathrm{pH}$ results in the deposition of calcium, phosphate and fluoride.

Studies have shown that SMH measurement is a convenient technique that can be used to determine enamel surface hardness [19]. It is a functional method to detect fine microstructure, non homogenous areas prone to cracking in dental enamel.

Blue covarine was a new silica based whitening component. The idea behind blue covarine formulation was contemplated to provide teeth whitening.

The present study was undertaken to evaluate the remineralization outcome associated with two remineralizing agents in an early enamel demineralization in vitro models using Pepsodent whitening toothpaste and Colgate Maxfresh toothpaste. The results showed that both toothpastes were able to yield similar levels of microhardness following remineralization procedures. However, Colgate Maxfresh showed a slightly higher level in microhardness in comparison with Pepsodent Whitening toothpaste although the results were not statistically significant.

The values of surface microhardness indicate that remineralization of enamel is more with Colgate Maxfresh toothpaste. This high remineralizing capacity of Colgate Maxfresh may be attributable to its high calcium and phosphate level content or its particle size which can enter the enamel surfaces.

The silica based whitening toothpaste containing blue covarine has been formulated for an effective extrinsic stain removal. However, the increase in stain removal efficacy did not give a collateral increase in abrasion as demonstrated using in vitro model [16]. However, in the current study this toothpaste has not reported an adequate remineralization of enamel or dentine.

Results of the present study are in accordance with studies conducted by Vahid Golpayegani et al and Karlinsey et al [20] for evaluating the remineralization efficacy. Chintan Joshi et al summarized effectively that Fluoride which was employed as a positive control group resulted in increased microhardness values of lesions by inhibiting the additional demineralization of existing carious lesions.

According to studies, the presence of small and intercrystalline spaces, enamel cracks, rod sheaths and other defects in enamel structures allows the partial penetration of certain ions and molecules through it. In the current study, both Colgate Maxfresh and Pepsodent Whitening yielded predominant results after remineralization although there was a statistically significant difference between the remineralisation efficacy between the two groups of toothpastes.

Since the present study was conducted in an in vitro setting, the oral environment could not be simulated to match the exact in vivo conditions. Hence, more translational research on dental tissues remineralization is required to identify potential therapeutic remineralizing properties of blue covarine.

With this basis, we can confirm that Colgate Maxfresh is an excellent material for remineralization of white spot or initial enamel caries as compared to Pepsodent Whitening toothpaste.

\section{Conclusion}

Under the condition of this study, these conclusions can be derived.Conventional fluoridated toothpastes effectively remineral- 
izes initial enamel caries when compared to toothpastes containing blue covarine.

\section{References}

[1]. Appanaitis IB, Lambert WE, Schwarz E, Lasarev MR, Watson BM. Dental Caries and Otitis Media Among Schoolchildren in Palau. Hawaii J Health Soc Welf. 2020 Jun 1;79(6 Suppl 2):33-39. Pubmed PMID: 32596676.

[2]. Al Haddad T, Khoury E, Farhat Mchayleh N. Comparison of the Remineralizing Effect of Brushing with Aloe vera versus Fluoride Toothpaste. Eur J Dent. 2021 Feb;15(1):133-138. Pubmed PMID: 33032331.

[3]. Souza BM, Comar LP, Vertuan M, Fernandes Neto C, Buzalaf MA, Magalhães AC. Effect of an Experimental Paste with Hydroxyapatite Nanoparticles and Fluoride on Dental Demineralisation and Remineralisation in situ. Caries Res. 2015;49(5):499-507. Pubmed PMID: 26278685.

[4]. Goldberg M. From the Initial Carious Lesion of Enamel to the Early Development of Coronal Dentin Carious Lesion. InUnderstanding Dental Caries 2016 (pp. 63-71). Springer, Cham.

[5]. Guzmán-Armstrong S, Fontana M, Nascimento M, Zandona A. Caries Management, An Issue of Dental Clinics of North America, E-Book. Elsevier Health Sciences; 2019 Aug 30.

[6]. Selivany BJ, Al-Hano F. The Effect of Remineralizing Toothpastes on Enamel Surface Roughness after Hybrid Laser Bleaching (An In vitro Study). Journal of Baghdad College of Dentistry. 2015;27(4):1-7.

[7]. Juntavee A, Juntavee N, Hirunmoon P. Remineralization Potential of Nanohydroxyapatite Toothpaste Compared with Tricalcium Phosphate and Fluoride Toothpaste on Artificial Carious Lesions. Int J Dent. 2021 Mar 20;2021:5588832. Pubmed PMID: 33824661.

[8]. Shetty S, Hegde MN, Bopanna TP. Enamel remineralization assessment after treatment with three different remineralizing agents using surface microhardness: An in vitro study. J Conserv Dent. 2014 Jan;17(1):49-52. Pubmed PMID: 24554861

[9]. Alafifi A, Yassen AA, Hassanein OE. Effectiveness of polyacrylic acid-bioactive glass air abrasion preconditioning with NovaMin remineralization on the microhardness of incipient enamel-like lesion. J Conserv Dent. 2019 Nov-Dec;22(6):548-553. Pubmed PMID: 33088063.

[10]. El-Damanhoury HM, Elsahn NA, Sheela S, Bastaty T. In Vitro Enamel Remineralization Efficacy of Calcium Silicate-Sodium Phosphate-Fluoride
Salts versus NovaMin Bioactive Glass, Following Tooth Whitening. Eur J Dent. 2021 Feb 23. Pubmed PMID: 33622008

[11]. Assiry AA. Evaluation of remineralization potential of casein phospho-peptide with amorphous calcium phosphate fluoride (CPP-ACPF) on demineralised enamel surfaces.

[12]. Buzalaf MA, Cardoso CD, Magalháes AC. Low-fluoride toothpastes may not lead to dental fluorosis but may not control caries development. Standard fluoride toothpastes can control caries development but may lead to dental fluorosis. Journal of Evidence Based Dental Practice. 2013 Dec $1 ; 13(4): 148-50$.

[13]. Buzalaf MAR, Levy SM. Fluoride intake of children: considerations for dental caries and dental fluorosis. Monogr Oral Sci. 2011;22:1-19. Pubmed PMID: 21701188.

[14]. Baig M, Cook RB, Pratten J, Wood R. Evolution of wear on enamel caused by tooth brushing with abrasive toothpaste slurries. Wear. 2020 Dec 11:203580.

[15]. Instant Tooth Whitening Effect of Toothpaste with Blue Covarine on Enamel and Abrasive Dentin [Internet]. Korean Journal of Dental Materials. 2011.

[16]. Joiner A. A silica toothpaste containing blue covarine: a new technological breakthrough in whitening. Int Dent J. 2009 Oct;59(5):284-8. Pubmed PMID: 19998663.

[17]. hetty S, Hegde MN, Bopanna TP. Enamel remineralization assessment after treatment with three different remineralizing agents using surface microhardness: An in vitro study. J Conserv Dent. 2014 Jan;17(1):49-52. Pubmed PMID: 24554861.

[18]. Saini J, Gupta A, Srivastava A, Kataria S. Agents to Maintain Tooth Integrity: An Equilibrium between Remineralization and Demineralization-A Review. International Journal of Dental and Medical Speciality. 2019;6(1):9-14.

[19]. Maarafi AJ, Hara AT, Levon JA, Chu TG, Eckert GJ, Lippert F. The Effects of Fluoride Treatment Time and Concentration on In Vitro Caries Lesion Demineralisation and Remineralisation. Oral Health Prev Dent. 2018;16(6):557-562. Pubmed PMID: 30574610.

[20]. Amaechi BT, Karthikeyan R, Mensinkai PK, Najibfard K, Mackey AC, Karlinsey RL. Remineralization of eroded enamel by a $\mathrm{NaF}$ rinse containing a novel calcium phosphate agent in an in situ model: a pilot study. Clin Cosmet Investig Dent. 2010 Aug 25;2:93-100. Pubmed PMID: 23662086. 